seems to be a reciprocal relationship in the expression of this F9 antigen and the $\mathrm{H}-2$ antigens--F9 in the embryo and $\mathrm{H}-2$ in the adult. The $\mathrm{H}-2$ region lies close to $T / t$ and is frequently tied to it in wild mouse populations by the presumably advantageous suppression of crossing over which is a property of $t$ alleles. It is therefore of interest that genes at four loci within a region of some 15 centimorgans on chromosome $17-T / t$, $H-2 K, \quad H-2 D$ and $T l a-$ have been shown to specify membrane glycoproteins of similar structure including the incorporation in each of them of a small subunit which is probably $\beta-2$ microglobulin. This was the main argument advanced by Artzt and Bennet (Nature, 256, 545; 1975) in support of the hypothesis that this family of four loci are descendants of an ancestral locus that acquired the property of cell surface perception as a condition of metazoan evolution. The immune system can therefore be considered as a special case of adaptive differentiation using as its cornerstones genes which may be reduplications of genes coding for receptors that are important in more primitive cell recognition.

We are grateful to the Wellcome Trust for a contribution to travelling expenses.

\section{Slugs and plants}

\section{from Robert M. May}

Much information about the natural history of plants and animals may be assembled in an orderly framework by noting that the world tends to provide a continuum of environments, ranging from the unpredictable (where evolutionary pressures are for rapid population growth to exploit the transient good times), through to predictable and biologically crowded environments (where evolutionary pressures are to be a good competitor). These notions, which reach back to Darwin, are commonly formalised in terms of the extremes of "r-selection" and " $K$ selection", respectively (see Nature, 257, 737; 1975).

One application of these ideas is to the phenomenon of succession. This phenomenon, whereby untended open space tends to revert to weeds, then shrubs, and eventually to woodland, is familiar to all possessors of suburban lawns. The temporal procession from early succession to late succession and climax is a paradigmatic example of a gradient from r-selection to $\mathbf{K}$ selection. On a small scale, such gradients from $\mathrm{r}$ - to $\mathrm{K}$-selection have been documented in populations of dandelions (Gadgil and Solbrig, $A m$. Nat., 106, 14-31; 1972), goldenrods (Abrahamson and Gadgil, Am. Nat., 107, 651-661; 1973) and other wild flowers growing in patches subject to significantly different degrees of disturbance. McNaughton (Am. Nat., 109, 251-261; 1975) has recently supplemented this work with a meticulous study of populations of cattails (Typha) in a variety of sites with differing lengths of frost-free growing periods. He shows the relatively unpredictable locations with a short growing season favour r-selected genotypes which have faster development, produce more offspring (seeds), but invest less energy in each offspring (smaller seeds) and put less premium on traits conferring competitive ability, such as height (to shade out other plants).

A somewhat deeper test of the ideas comes from considering the relation between plants and the beasts that eat them, as a function of successional stage. Compared with late successional plants, those in early succession should invest relatively more of their resources in growth (and reproduction), and relatively less in defence against herbivores. This is so, both for the reasons outlined above, and because the patchy and unpredictable distribution associated with early succession itself provides a degree of escape from herbivores. Thus early successional plant species should provide better food sources for generalised herbivores than do later successional and climax plants. Cates and Orians (Ecology, 56, $410-418 ; 1975$ ) have recently tested this by taking 100 plant species, of three growth forms and from different seral stages, and determining their short-term palatability to two slug species, one native to western Washington (Ariolimax columbianus) and one introduced from Europe (Arion ater). Palatability of a given test plant was measured as the ratio of test material eaten to control material eaten, in a well-defined laboratory setting. The results showed that early successional annuals were significantly more palatable than early successional perennials, which in turn were significantly more palatable than later successional species. This validation of theoretical expectations was clear cut, in that no correlation was found between palatability and evolutionary association of the herbivores with particular plant species.

Specifically, Cates and Orians define a "palatability index" as the ratio of $\log$ (amount of test material eaten) to $\log$ (amount of control material eaten). Then for the native slug Ariolimax, the average palatability index for early successional annuals and biennials was 0.96 , for early successional perennials
0.77 , and for later successional and climax plants 0.46 . The corresponding figures for the European slug Arion were $0.99,0.69,0.40$.

A more detailed field and laboratory study of one particular slug-plant system has also been carried out by Cates (Ecology, 56, 391-400; 1975). Using wild gingėr (Asarum caudatum) and again the native slug $A$. columbianus, he showed the plant populations were polymorphic for growth rate, seed production, and palatability to the slug. In habitats where slugs were relatively rare, populations of wild ginger were dominated by individuals allocating more energy to growth rate and seed production, and less to the production of biochemicals that slugs find nasty. Conversely, in habitats where the slugs were abundant, the more $\mathrm{K}$-selected individuals predominated.

Cates and Orians note that slugs are not "representative" generalised herbivores, because they tend to avoid grasses. Nonetheless, the successional trends they have documented march with the results of other studies, and indicate "broad patterns in the ways plants and herbivores have mutually iftfluenced one another's evolution."

\section{Biochemical factors in schizophrenia}

\section{from Richard Rodnight}

The paper by A. G. M. Pearson and A. J. Turner in this issue of Nature (page 173) bridges two areas of research-transmethylation and folic acid metabolism-both of which have potential significance for studies of the biochemical basis of psychotic behaviour in man. A disturbance of transmethylation has often been proposed as a possible factor in the aetiology of schizophrenia, but until recently there were few clues as to the pathways which might be involved. A possible mechanism came to light with the discovery in 1961 by J. Axelrod (Science, 134, 343) of a methyltransferase enzyme in rabbit lung that transfers methyl groups from $\mathrm{S}$ adenosylmethionine (SAM) to the naturally occurring indoleamine tryptamine to form mono- and dimethyltryptamine (DMT). The latter compound has been known for many years to induce in normal subjects a model psychosis when administered parenterally, an observation which evokes the suggestion that some of the typical symptoms of schizophrenia may be due to the aberrant production of endogenous DMT in the affected individuals. There is indeed good evidence now that the body does convert minute fractions of its stores of 